\title{
Open Source Systems Engineering Guides, Deployment Packages and Support Tools for Very Small Enterprises - A Case Study
}

\author{
Claude Y. Laporte \\ École de technologie supérieure \\ Department of Software and IT Engineering \\ 1100 Notre-Dame Street West, Montréal \\ Québec H3C 1K3, Canada, \\ Claude.Y.Laporte@etsmtl.ca
}

\author{
Ronald Houde \\ Mannarino Systems \& Software \\ 100 Alexis-Nihon Blvd, Suite 650 \\ Saint-Laurent, Québec H4M 2P2, Canada \\ Ronald.Houde@mss.ca
}

Copyright $(\mathcal{C} 2015$ by C. Y. Laporte, R. Houde, Permission granted to INCOSE to publish and use.

\begin{abstract}
Very small entities (VSEs) play an increasingly important role in the global economy. The products they develop are often integrated into products made by larger enterprises. The "Big League" clients, furthermore, demand of the VSEs that they assume a much broader role, spanning the entire development life-cycle of the product instead of being limited to a "build-toprint" approach. To address this new reality, to exploit the lean and efficient nature of VSEs and to adapt to their typical budget and resource constraints, the ISO/IEC 29110 systems engineering standards, management and engineering guides were developed from ISO/IEC/IEEE 15288. In addition, and by design, the standard is supported by Deployment Packages, software tools and training kits. The INCOSE VSE working group developed the deployment packages. A deployment package is a set of artefacts designed to facilitate the implementation of a standard or a set of practices in a VSE. In tune with the need for low cost and flexibility, Open Source software tools are emerging to complete "Big League" development life-cycle toolsets, which are often out-of-reach to VSEs. Finally, to make the deployment of the standard possible in the VSE, training packages, supported by relevant pilot projects help VSE personnel learn how to apply all of the above.
\end{abstract}

\section{Introduction}

Industry recognizes the value of Very Small Entities (VSEs), i.e., enterprises, organizations, departments or projects with up to 25 people, in contributing valuable products and services. A large majority of enterprises worldwide are VSEs. In Europe, for instance, as illustrated in Table 1 , over $92 \%$ of enterprises are micro-enterprises. They have fewer than nine employees. Micro enterprises account for $70 \%$ to $90 \%$ of enterprises in OECD countries and about $57 \%$ in USA. 


\section{5th Annual INCOSE International Symposium (IS2015) \\ Seattle, July 13-16, 2015}

Table 1: Size of enterprises in Europe (Moll 2013)

\begin{tabular}{|l|r|r|r|r|}
\hline \multicolumn{1}{|c|}{ Type of enterprise } & $\begin{array}{r}\text { Number } \\
\text { of employees }\end{array}$ & $\begin{array}{c}\text { Annual } \\
\text { turnover } \\
\text { (EURO) }\end{array}$ & $\begin{array}{c}\text { Number } \\
\text { of enterprises } \\
\text { (\% of overall) }\end{array}$ & $\begin{array}{c}\text { Number } \\
\text { of enterprises }\end{array}$ \\
\hline Micro-enterprises & $1-9$ & $\leq 2$ million & $92.2 \%$ & 19968000 \\
\hline Small enterprises & $10-49$ & $\leq 10$ million & $6.5 \%$ & 1358000 \\
\hline Medium enterprises & $50-249$ & $\leq 50$ million & $1.1 \%$ & 228000 \\
\hline SMEs, total & 87100000 & & $99.8 \%$ & $21544000^{\star}$ \\
\hline Large enterprises & $>250$ & $>50$ million & & \\
\hline $\begin{array}{l}\text { Large enterprises, } \\
\text { Total }\end{array}$ & 42900000 & & $0.2 \%$ & 43000 \\
\hline * Independent companies only, excluding legally independent companies that are part of large enterprises. \\
\hline
\end{tabular}

Many international standards, such as ISO/IEC/IEEE 15288 (ISO 2015a), have been developed to capture proven management and engineering practices. In the last decades, under risk sharing partnerships meant to dilute the cost of developing complex products, large companies have progressively moved into risk sharing partnerships with their suppliers. As a result, "partners began to take over not only investments in tools and non routine engineering and infrastructure but also to participate more directly in investments and project development, thereby acquiring rights to their future sales income." specifications traditionally prepared by the upper tier client, now had to be developed by their subordinate lower tier risk sharing partners. In sectors such as aerospace, medical devices, automotive, rail transportation, atomic energy and industrial processes, the transfer entailed the production of a range of process artefacts that range from plans, requirements specification, design descriptions, source code/netlists and test procedures. Over time, such risk sharing partnerships were pushed down to lower tier suppliers in the supply chain, reaching progressively smaller businesses that were ill-equipped to deal with the complete span and lifecycle of product development activities integrated with higher tier processes and tools. The existing system and software development life-cycle standards, furthermore, were not written with VSEs in mind, were difficult and burdensome to tailor and apply in such settings and require staff resources to manage, thereby increasing the bureaucratic burden and overhead costs. A need therefore arose to provide VSEs with solutions that would keep bureaucratic and overhead costs down while achieving the performance and maturity benefits sought by larger organizations of existing international engineering standards, along with the concepts, processes and practices involved. An ISO Working Group (ISO/IEC JTC1 SC7 $7^{2}$ Working Group 24) was established to address these challenges by developing standards and guides adapted to the needs of VSEs.

\footnotetext{
${ }^{1}$ P. Figueiredo, G. Silveira \& R. Sbragia, RISK SHARING PARTNERSHIPS WITH SUPPLIERS: THE CASE OF EMBRAER, University of Sao Paulo, Faculty of Economics, Accounting and Business Administration, Sao Paulo, Brasil, published in the Journal of Technology Management and Innovation, Volume 3, Issue 1

(http://www.jotmi.org/index.php/GT/article/view/art70)

${ }^{2}$ International Organization for Standardization/ International Electrotechnical Commission Joint Technical Committee 1/ Sub Committee 7
} 


\section{5th Annual INCOSE International Symposium (IS2015) \\ Seattle, July 13-16, 2015}

This paper presents the application of the new systems engineering ISO/IEC 29110 standard developed for VSEs performing systems development with up to 25 people. More specifically, we will:

- Provide an overview the ISO/IEC 29110 standards and guides for VSEs;

- Describes the set of nine (9) Deployment Packages (DPs) covering the span of the systems engineering life-cycle and describe in more detail the Requirements Engineering (RE) DP;

- Describe one available Open Source tool available to support the RE Deployment Package, the Eclipse Requirements Management Framework (RMF);

- In the context of a Pilot Project, show how a collaborative Training Kit was developed to help VSEs implement the ISO/IEC 29110 Requirement Engineering Deployment Package.

\section{Overview of ISO/IEC 29110 Systems Engineering Standards and Guides}

The first version of ISO/IEC 29110 is a four-stage roadmap, also called profiles (Entry, Basic, Intermediate, Advanced) is applicable to VSEs that do not develop critical systems. VSEs targeted by the Entry profile are those working on small projects (e.g., at most six person-months of effort) and for start-ups. The Basic profile describes the development practices of a single application by a single project team with no special risk or situational factors. The Intermediate profile is targeted at VSEs developing multiple projects with more than one team within the organization. The Advanced profile is targeted at VSEs wishing to sustain and grow as independent competitive businesses.

The ISO/IEC 29110 documents are targeted by audience as described in Table 2.

Table 2: ISO/IEC 29110 target audience (adapted from ISO 2014a)

\begin{tabular}{|c|l|l|}
\hline ISO/IEC 29110 & \multicolumn{1}{|c|}{ Title } & \multicolumn{1}{|c|}{ Target audience } \\
\hline Part 1 & Overview & $\begin{array}{l}\text { VSEs and their customers, assessors, standards } \\
\text { producers, tool vendors and methodology vendors. }\end{array}$ \\
\hline Part 2 & $\begin{array}{l}\text { Framework and } \\
\text { taxonomy }\end{array}$ & $\begin{array}{l}\text { Standards producers, tool vendors and methodology } \\
\text { vendors. } \\
\text { Not intended for VSEs. }\end{array}$ \\
\hline Part 3 & $\begin{array}{l}\text { Certification and } \\
\text { Assessment guide }\end{array}$ & $\begin{array}{l}\text { VSEs and their customers, assessors, accreditation } \\
\text { bodies. }\end{array}$ \\
\hline Part 4 & Profile specifications & $\begin{array}{l}\text { Standards producers, tool vendors and methodology } \\
\text { vendors. } \\
\text { Not intended for VSEs. }\end{array}$ \\
\hline & $\begin{array}{l}\text { Management and } \\
\text { engineering guide }\end{array}$ & VSEs and their customers. \\
\hline
\end{tabular}




\section{5th Annual INCOSE International Symposium (IS2015) \\ Seattle, July 13-16, 2015}

Parts 1, 2 and 3, which are freely available from ISO, are the same for both the software engineering (SW) and systems engineering (SE) domains, while parts 4 and 5 have different content for these two domains.

Finally, it is worth mentioning that, even though the processes are described according to a sequential/waterfall approach, the ISO/IEC 29110 series is not intended to dictate the use of any particular life cycle such as waterfall, iterative, incremental, evolutionary or agile.

The ISO/IEC 29110 standard has a formal certification process. This process has been created taking into account the needs of software and systems development VSEs, so that audits should not be too expensive or time consuming. The certification scheme is based on ISO standards for certification body requirements and auditor capability requirements. A VSE is expected to invest about 85 hours for the certification process. The cost of an ISO/IEC 29110 initial audit is about $\$ 1,500$. This audit cost does not include the auditor's travel expenses. It is estimated that the cost of each one of the 2 surveillance audits, excluding the travel costs of the auditor, will be about $\$ 1,200$. The effort and expenses invested by a VSE for an audit is quite small compared to a typical CMMI-DEV assessment.

The reader will find more details about the development of ISO/IEC 29110 systems engineering standards and freely available guides in papers presented at the 2012 and 2014 INCOSE Symposia (Laporte et al. 2012, 2014a).

\section{Engineering and Management Guide for the Systems Engineering Basic Profile}

The systems engineering Basic profile, illustrated in Figure 1, is composed of two processes: Project Management (PM) and System Definition and Realization (SR). As defined in ISO/IEC 29110, the purpose of the PM process is to establish the system engineering tasks and carry them

out in a systematic way, which makes it easier to meet the project objectives with regard to expected quality, time and cost. The purpose of the System Definition and Realization (SR) process is the systematic performance of the analysis, design, construction, integration, verification and validation activities of new or modified systems according to the specified requirements.

As illustrated in figure 1, the PM process uses the acquirer's Statement of Work (SOW) to establish the project plan and develop the product requested using the SR process. 


\section{5th Annual INCOSE International Symposium (IS2015) \\ Seattle, July 13-16, 2015}

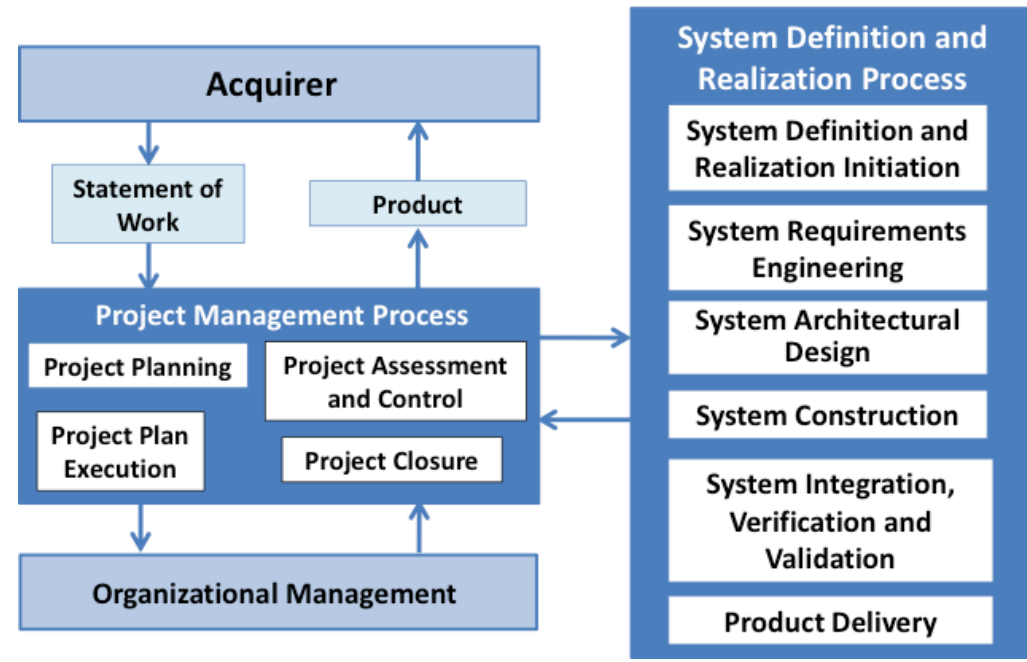

Figure 1. Processes of the systems engineering Basic Profile (Laporte 2014b)

The ISO/IEC 29110 standards and guides for systems engineering are designed to work hand-inhand with the ones for software engineering.

\section{Deployment Packages to Support the Systems Engineering Basic Profile}

The INCOSE VSE Working Group defined a set of guidelines explaining in more detail the processes defined in the Basic profile. These guidelines are freely accessible to VSEs on the Internet as a collection of Deployment Packages (DPs). A DP is a set of artefacts developed to facilitate the implementation of a set of practices for the selected framework in a VSE (Laporte 2014b). Since the INCOSE handbook is a 'how to' document, it was used to develop the set of DPs. DPs are designed such that a VSE can implement its content without having to implement the complete Basic profile at the same time. The table of contents of a Deployment Package is illustrated in Table 3.

Table 3: Table of contents, SE Deployment Package (adapted from Laporte et al. 2012)

\begin{tabular}{|l|}
\hline 1. Introduction \\
\hline Purpose of this document \\
\hline Key Definitions \\
\hline 2. Why this process is important \\
\hline 3. Overview of main tasks \\
\hline 3.1 Tasks \\
\hline 3.2 Roles and artefacts \\
\hline 3.3 Activity life cycle and examples of life cycles \\
\hline Appendix A Templates \\
\hline Appendix B Checklists \\
\hline Appendix C Coverage Matrices (ISO 15288, ISO 9001, CMMI) \\
\hline Appendix D Tools \\
\hline Appendix E References \\
\hline Appendix F Evaluation Form \\
\hline
\end{tabular}




\section{5th Annual INCOSE International Symposium (IS2015) \\ Seattle, July 13-16, 2015}

Figure 2 illustrates the set of SE DPs for the Basic profile, which is available on the Internet ${ }^{3}$ and on the INCOSE VSE page.

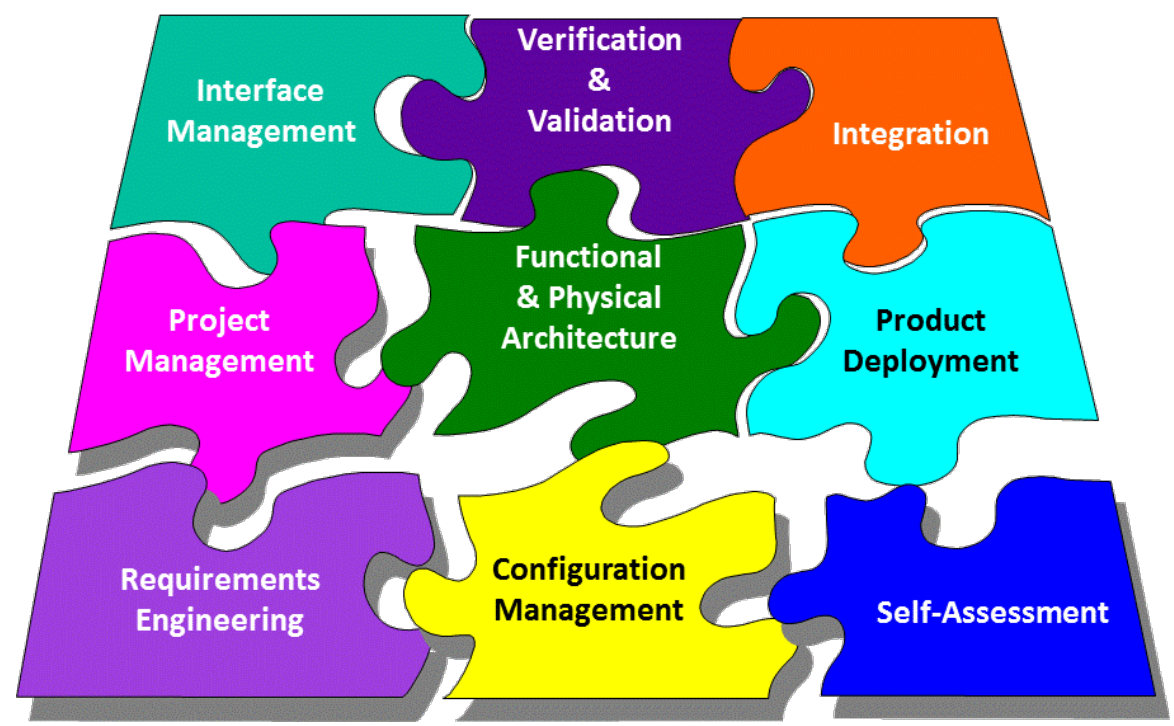

Figure 2. Deployment Packages for the SE Basic profile

The Requirements Engineering DP defines a collection of activities, tasks, steps, roles, artefacts, templates and checklists for those work products that achieve the objectives of ISO/IEC 29110 for:

- the definition of Acquirer/Stakeholder Requirements;

- the definition of System Requirements;

- the decomposition of System Requirements into System Element Requirements using the architecture defined in the Functional \& Physical Architecture DP;

- the creation of traceability links between each level of requirement decomposition;

- the preparation of the System Specification;

- the preparation of System Element Specifications (for hardware or software subsystems); and

- the verification and validation of the requirements.

The Requirements Engineering DP identifies candidate Requirements Management Tools suitable for VSEs and provides instructions for tailoring the tools to support the DP. One of those tools is the Eclipse Requirements Management Framework (RMF). Two checklists are provided to evaluate the quality of the requirements developed by the VSE and the specification assembling and structuring the collection of individual requirements. The checklists apply worldclass standards such as ISO/IEC 29148 and the INCOSE Guide for Writing Requirements.

The Functional \& Physical Architecture DP achieves the same purpose as the Requirements Engineering DP for:

\footnotetext{
${ }^{3}$ http://profs.etsmtl.ca/claporte/English/VSE/index.html (Deployment Packages)
} 


\section{5th Annual INCOSE International Symposium (IS2015) \\ Seattle, July 13-16, 2015}

- the conduct of system architecture definition trade studies (functional architecture);

- the definition of System Elements and the interfaces between them (physical architecture);

- the verification of the System Architecture and Sub-System Specifications.

The Interface Management DP repeats the process for the definition, management and control of interfaces at all levels of the system.

The Integration DP shows how System Elements are assembled and integrated into a complete system in accordance with an Integration Plan.

The Verification \& Validation DP details how a requirements-driven verification planning and execution process can be implemented by a VSE for a System and how that System is validated ultimately against captured Acquirer/Stakeholder Requirements.

The Product Deployment DP defines how the System is produced and deployed with the Acquirer, including the transition from an existing system to the new one and the training of users.

The Project Management DP shows how all the activities are planned and executed and risks (project or technical) are identified and managed according to the threat they represent to the project.

The Configuration Management DP defines how all the artefacts created by the VSE, including the System Elements and System itself are placed under configuration control.

Finally, the Self-Assessment DP provides instructions, templates and checklists allowing a VSE to evaluate how well they have applied the collection of DPs to their processes to achieve the objectives of the applicable ISO/IEC 29110 profile.

\section{Open Source Tools Developed to support DPs}

One of the primary constraints of VSEs is the limited access their resources and staffing permit them in terms of life-cycle development tools. Most cannot afford the burden of "Big League" tools and have been relegated to using word processing and spreadsheet tools to manage requirements. Current commercially available requirements management tools add two further constraints that will often discourage VSEs: 1) the tool's flexibility requires of the RM tool that it be custom-fitted to the VSEs needs and that support staff or contractors be on hand to provide training, tailoring and implementation support throughout the span of the project; or 2) the RM tool implements a specific product development life-cycle process that is not compatible with the often "lean" processes used by the VSE. Whereas basic word-processing and spreadsheet tools can be acceptable for a small number of requirements and limited linking among them, their capabilities are rapidly challenged on medium to large size projects. After a somewhat shaky 


\section{5th Annual INCOSE International Symposium (IS2015) \\ Seattle, July 13-16, 2015}

start, Open Source requirements management tools have taken a significant turn with the emergence of the Eclipse Requirements Management Framework (RMF), ${ }^{4,5}$, the Object Management Group (OMG) Requirements Interchange Format (ReqIF) ${ }^{6}$ and the support of such working groups as Polarsys ${ }^{7}$, created by large industry players and by tools providers to collaborate on the creation and support of Open Source tools for the development of embedded systems. However, those tools are often generic in nature and require some tailoring which is addressed in the RE Deployment Package.

RMF is a framework for working with textual requirements, structured as ReqIF models. RMF uses natively ReqIF, allowing you to exchange requirements with many industry applications like IBM Rational DOORS ${ }^{\circledR}$ or PTC integrity ${ }^{\circledR}$. Using ReqIF as its native data storage structure provides another significant advantage for VSEs by allowing them to exchange ReqIF export files directly with upper tier partners and skipping the tool tailoring/customization step entirely. ProR was developed as a RMF Graphical User Interface (GUI) that allows manipulating requirements within a RMF environment. Operating within the Eclipse Integrated Development Environment (IDE), it allows a requirements engineer to open ReqIF files with a click, allowing you to immediately inspect and edit files. Powerful extensions exist for dealing with rich text, ReqIFz-Archives and others. Those extensions are made available in integration with UML/SysML modeling tools and within emerging distributions such PolarSys, illustrated in Figure 3, and openETCS ${ }^{8}$.

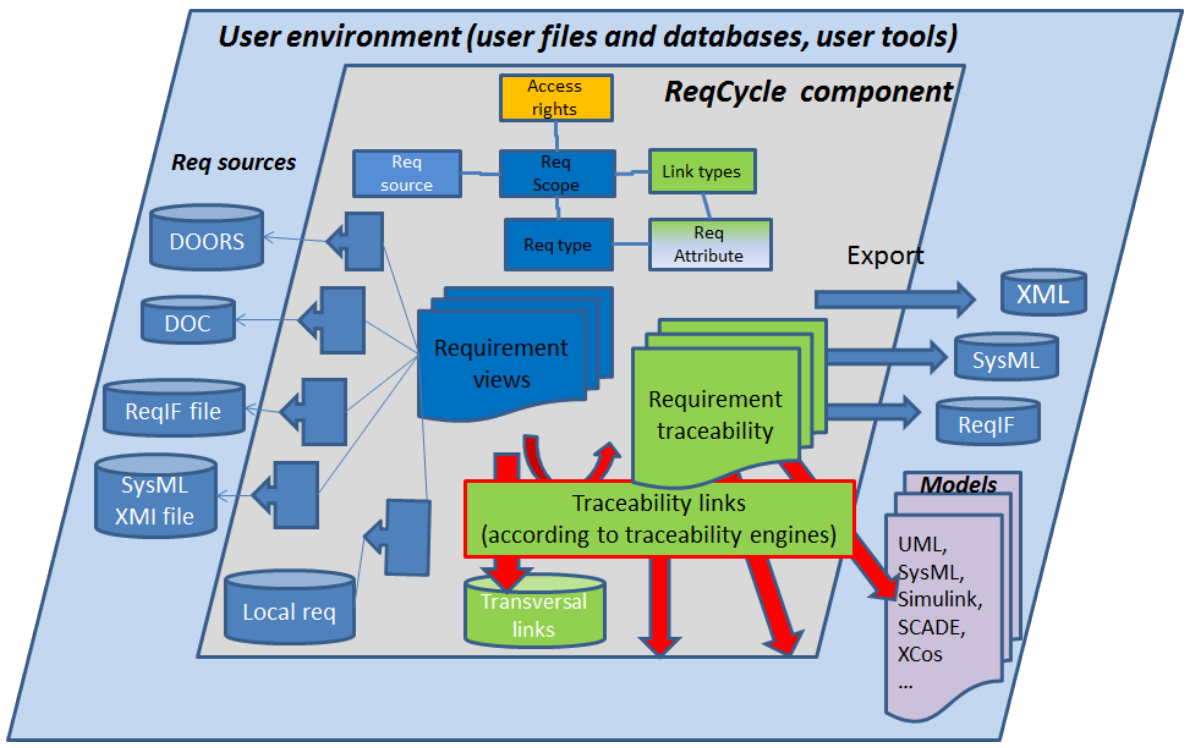

Figure 3. Polarsys ReqCycle Requirements Management Component

\footnotetext{
${ }^{4}$ http://www.eclipse.org/rmf/

${ }^{5}$ Under the leadership of Michael Jastram

${ }^{6} \mathrm{http}$ ://www.omg.org/spec/ReqIF/

7 http://www.polarsys.org

8 http://openetcs.org/tool/
} 


\section{5th Annual INCOSE International Symposium (IS2015) \\ Seattle, July 13-16, 2015}

\section{Training Kit and Pilot Project}

At this stage, two of the three pieces of the equation are in place: the ISO/IEC 29110 and the Requirements Engineering Deployment Package provide the Process piece; an Open Source Framework, constructed around the Eclipse Requirements Management Framework, provides the Tool piece. We now need to bring People into the equation. A survey of enterprises done in (Land 1997) identified very specific needs they have in order to achieve an acceptance of standards. Those needs include:

- User training course

- Examples of deliverables

- Deliverable templates

- CASE tool support for documentation generation

- On-line or phone support

- Educators resource/support

An inexpensive, publicly licensed (i.e. allowing a VSE to tailor and adapt to its needs with as few constraints as possible) and easily deployable training package was therefore needed to allow VSEs to deploy an effective Systems Engineering life-cycle process. Such a Training Kit was developed by the Eclipse foundation", in collaboration with a team of practitioners from around the world.

Since requirements are the cornerstone of a requirement-centric development life-cycle, it should not come as a surprise that the RE DP was the first of the Systems Engineering DP selected for development. It will serve as the proving ground upon which the other Systems Engineering DPs will be developed under the "Systems Engineering for VSEs" INCOSE Working Group.

As a pilot project to use the DPs and tools, the RE DP Training Kit, has been constructed around Case Studies that can be extended to apply to all the Systems Engineering DPs and the entire life-cycle of a Systems Engineering effort (i.e. hardware, software, organizational processes, etc.). The Case Studies, used in the Training Kit, are: 1) the Traffic Light Control System; and 2) the Autonomous Rover ${ }^{10}$.

The Traffic Light Control System was selected to develop the draft RE training tutorial. The Tutorial is available as a LaTex document ${ }^{11}$.

The Autonomous Rover case was selected for a pilot project because it represents a typical System development problem (i.e. includes both hardware and software elements). Also, it is sufficiently simple that a complete solution can be developed during the training period and allows students to become proficient with the application of the System Requirements Engineering Process for a VSE, the artefact templates and the RE Tool.

\footnotetext{
${ }^{9} \mathrm{http}: / /$ jastram.github.io/teaching/

${ }^{10} \mathrm{https} / / /$ polarsys.org/wiki/PolarSys Rover Demo

${ }_{11}^{11} \mathrm{https} / / /$ github.com/jastram/teaching/tree/master/SE
} 


\section{5th Annual INCOSE International Symposium (IS2015) \\ Seattle, July 13-16, 2015}

The RE DP Training Material for either case has for objective to satisfy Goal 1 of Step 0 of the Autonomous Rover project, which is to gather the first set of requirements. The set, of which a sample is shown in Table 4, consists of functional, non-functional, hardware and safety requirements to be implemented in three (3) phases of the Autonomous Rover development project. Whereas the RE DP focuses on the management and engineering of textual requirements, the Case Study is designed from its inception to be extendable to Model-Base techniques, methodologies and tools.

Table 4: Sample of Autonomous Rover project requirements

\begin{tabular}{|l|l|l|l|l|}
\hline \multicolumn{1}{|c|}{ Identifier } & \multicolumn{1}{|c|}{ Description } & Target Version & Category & Comment \\
\hline ROVER_FUNC_010 & $\begin{array}{l}\text { The Rover must support } \\
\text { various payloads } \\
\text { (sensors/camera/robotic } \\
\text { arm) thanks to a } \\
\text { pluggable software } \\
\text { architecture }\end{array}$ & 1.0 & Functional & \\
\hline ROVER_HARD_010 & $\begin{array}{l}\text { The Rover must be built } \\
\text { with the Polulu Dagu } \\
\text { Rover 5 platform }\end{array}$ & 1.0 & Hardware & \\
\hline ROVER_NFUNC_010 & $\begin{array}{l}\text { Battery must provide an } \\
\text { autonomy of at least } \\
\text { 10mn }\end{array}$ & 1.0 & Non Functional & $\begin{array}{l}\text { Will evolve to } \\
\text { 30mn autonomy } \\
\text { in V3.0 }\end{array}$ \\
\hline ROVER_SAFE_010 & $\begin{array}{l}\text { The Rover must avoid } \\
\text { crash in obstacles }\end{array}$ & 2.0 & Safety & \\
\hline
\end{tabular}

The Rover will be built with a low cost Polulu Dagu Rover 5 platform ${ }^{12}$ illustrated in Figure 4. The chassis includes a battery holder and two DC motors, with an independent drive train and a quadrature encoder for each tread. The outer dimensions of the chassis are approximately $24 \mathrm{~cm}$ (9.5") long, $23 \mathrm{~cm}\left(9^{\prime \prime}\right)$ wide, and $8 \mathrm{~cm}\left(3^{\prime \prime}\right)$ tall in its default, flattened configuration.

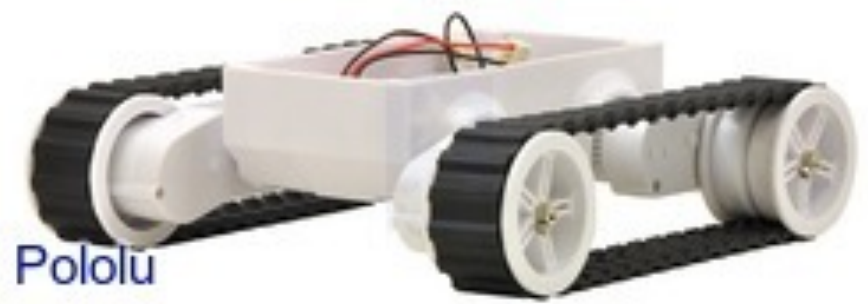

Figure 4. The Autonomous Rover

The training material has been collected in a GitHub project ${ }^{13}$ and is available under the Apache 2.0 License, which allows VSEs to use the material as is, or tailor it to meet their own needs. We also expect educators and trainers will use and improve the training material over time.

\footnotetext{
12 https://www.pololu.com/product/1551

${ }^{13}$ https://github.com/jastram/teaching/
} 


\section{5th Annual INCOSE International Symposium (IS2015) \\ Seattle, July 13-16, 2015}

\section{Conclusion and Future Work}

Industry recognizes the contribution of VSEs in terms of the valuable products and services they offer. A large majority of organizations worldwide have fewer than 25 people. Most system and software engineering standards were not easily applied in VSEs, where they were generally found difficult to understand and implement.

An ISO working group has developed a set of standards and guides to address the needs of VSEs developing system or software. ISO has published in 2014 the ISO/IEC 29110 Systems Engineering Basic profile (ISO 2014) and the Systems Engineering Entry profile in 2015 (ISO 2015b). The set of deployment packages, developed by the INCOSE VSE WG, to help implement the Basic profile, served as the basis to develop a publicly licensed Training Kit. The first of those Training Kits, covering the Requirements Engineering DP, teaches how an Eclipse Requirements Management Framework based tool can be used to implement the RE DP within a VSE. Being publicly licensed, the Training Kit can be adapted very easily to fulfill specific VSE needs.

Once the software engineering ISO/IEC 29110 Intermediate and Advanced profiles are ready, work will start on the two corresponding systems engineering profiles for VSEs. In parallel, a set of systems engineering Deployment Packages and corresponding Training Kits will be developed and deployed to support those profiles.

\section{Additional Information}

The following Web site provides more information, as well as articles by WG24 members and deployment packages for software and systems engineering:

http://profs.logti.etsmtl.ca/claporte/English/VSE/index.html

\section{References}

(ISO 2011a) ISO/IEC TR 29110-1:2011, Software Engineering - Lifecycle Profiles for Very Small Entities (VSEs) - Part 1: Overview. Geneva, Switzerland: International Organization for Standardization (ISO), 2011. Available at no cost from ISO at: http://standards.iso.org/ittf/PubliclyAvailableStandards/c051150_ISO_IEC_TR_291101_2011.zip

(ISO 2014) ISO/IEC TR 29110-6-5-2:2014 - Systems and Software Engineering - Systems Engineering Lifecycle Profiles for Very Small Entities (VSEs) - Management and engineering guide: Generic profile group: Basic profile, Geneva, Switzerland: International Organization for Standardization/International Electrotechnical Commission. Available at no cost from ISO at: http://standards.iso.org/ittf/PubliclyAvailableStandards/c063371_ISO_IEC_29110-5-

6_2_2014.zip 


\section{5th Annual INCOSE International Symposium (IS2015) \\ Seattle, July 13-16, 2015}

(ISO 2015a) ISO/IEC/IEEE 15288:2015, Systems and software engineering - System life cycle processes, Geneva, Switzerland: International Organization for Standardization/International Electrotechnical Commission, 2015.

(ISO 2015b) ISO/IEC TR 29110-6-5-1:2015 - Systems and Software Engineering - Systems Engineering Lifecycle Profiles for Very Small Entities (VSEs) - Management and engineering guide: Generic profile group: Entry profile, Geneva, Switzerland: International Organization for Standardization/International Electrotechnical Commission. Available at no cost from ISO at: http://standards.iso.org/ittf/PubliclyAvailableStandards

(ISO 2015c) ISO/IEC/IEEE 15289:2015, Systems and software engineering - Content of life cycle process information products (Documentation), Geneva, Switzerland: International Organization for Standardization/International Electrotechnical Commission.

(Land 1997) Land., S.K., Results of the IEEE Survey of Software Engineering Standards Users, Software Engineering Standards Symposium and Forum, 1997. 'Emerging International Standards'. ISESS 97, Third IEEE International, 1-6 June 1997 Page(s):242 - 270

(Laporte 2011) The Development and Experimentation of an International Standard for Very Small Entities Involved in Software Development, International Council on Systems Engineering (INCOSE) Workshop, January 29th 2011, Phoenix, Arizona.

(Laporte 2012) Laporte, Claude, Y, Fanmuy, Gauthier, Ptack, Ken, The Development of Systems Engineering International Standards and Support Tools for Very Small Enterprises, 22nd Annual International Symposium of the International Council on Systems Engineering, Rome, July 9-12, 2012. Available at:

http://www.etsmtl.ca/Professeurs/claporte/documents/publications/LAPORTE_INCOSE_2012.p $\underline{\mathrm{df}}$

(Laporte 2013a) Laporte, C.Y., Séguin, N., Villas Boas, G., Seizing the benefits of software and systems engineering standards, ISO Focus + , International Organization for Standardization, February 2013, pp 32-36.

http://www.iso.org/iso/home/news_index/iso_magazines/isofocusplus_index.htm

(Laporte 2013b) Laporte, C.Y., Chevalier, F., Maurice, J.-C., Improving Project Management for Small Projects, ISO Focus+, International Organization for Standardization, February 2013, pp 52-55. http://www.iso.org/iso/home/news index/iso magazines/isofocusplus index.htm

(Laporte 2013c) Laporte, C.Y., O'Connor, R., Fanmuy, G., International Systems and Software Engineering Standards for Very Small Entities, CrossTalk - The Journal of Defense Software Engineering, May/June 2013, Vol. 26, No 3, pp 28-33. Available at:

http://www.etsmtl.ca/Professeurs/claporte/documents/publications/Crosstalk_May_2013_Laport e.pdf 


\section{5th Annual INCOSE International Symposium (IS2015) \\ Seattle, July 13-16, 2015}

(Laporte 2014a) Laporte, Claude Y., Houde, R., Marvin, J., Systems Engineering International Standards and Support Tools for Very Small Enterprises, Paper to be presented at the 24th Annual International Symposium of INCOSE (International Council on Systems Engineering), Las Vegas, U.S., June 30-July 3, 2014. Available at:

http://www.etsmtl.ca/Professeurs/claporte/documents/publications/INCOSE-2014.pdf

(Laporte 2014b) Laporte, C.Y, O'Connor, R., A Systems Process Lifecycle Standard for Very Small Entities: Development and Pilot Trials, 21st European Software Process Improvement Conference (Euro SPI 2014), Luxembourg, June 25-27, 2014.

(Moll 2013) Moll, R., Being prepared - A bird's eye view of SMEs and risk management, ISO Focus +, Geneva, Switzerland: International Organization for Standardization, February 2013. Available at no cost at:

http://www.iso.org/iso/home/news_index/iso_magazines/isofocusplus_index/isofocusplus_2013/ isofocusplus_2013-02.htm

\section{Biography}

Dr. Claude Y. Laporte has been a professor since 2000 at the École de technologie supérieure (ÉTS), a 7,800-student engineering school, where he teaches software engineering. His research interests include software process improvement in small and very small enterprises, as well as software quality assurance. He has worked in defense and transportation enterprises for over 20 years. He received a Master's degree in Physics from the Université de Montréal, a Master's degree in Applied Sciences from the École Polytechnique de Montréal and a Ph.D. from the Université de Bretagne Occidentale (France). In addition, he was awarded an honorary doctorate by the Universidad de San Martin de Porres (Peru) in 2013. He is the Editor of ISO/IEC JTC1 SC7 Working Group 24, tasked to develop ISO/IEC 29110 life cycle standards and guides for Very Small Entities. He is the Co-chair of the INCOSE Systems Engineering for Very Small Entities WG. He is a member of INCOSE, IEEE, PMI and a member of the professional association of engineers of the Province of Québec (Ordre des ingénieurs du Québec). He is the co-author of two French books on software quality assurance published in 2011 by Hermes Science-Lavoisier and one English textbook, on the same topic, published by John Wiley and Sons in 2016.

Web site address: http://profs.etsmtl.ca/claporte/English/index.html

Ronald Houde is a Senior Systems Engineering Specialist with Mannarino Systems \& Software. He has over 30 years of experience in government and commercial safety- and mission-critical software and systems engineering. Employers and customers have included world leaders such as Esterline/CMC Electronics, Lockheed Martin, Bombardier Aerospace, CAE, BPR Énergie, Hydro-Québec, the Canadian Department of National Defence and the U.S. Army. His main areas of employment have been in the design, development, integration and installation of safety- 


\section{5th Annual INCOSE International Symposium (IS2015) Seattle, July 13-16, 2015}

critical software systems and programmable electronic devices. His clients in both industry and government benefit from his skills in training and mentoring, complex problem analysis and solving, and communication. He has also been involved in technical training and university and continuing education programs since the early 1990s. He is experienced in the conduct, management and continuous process improvement of software and systems engineering activities covering the entire life-cycle of operational, mission support and safety-critical software systems. He is an experienced instructor to technical military and civilian audiences, having developed and taught numerous Avionics, Avionics Databus and Requirements Engineering workshops. 